\title{
Induced HMGA1a expression causes aberrant splicing of Presenilin-2 pre-mRNA in sporadic Alzheimer's disease
}

\author{
T Manabe ${ }^{1,5,7}$, T Katayama ${ }^{\star, 1,5,7}$, N Sato ${ }^{1}$, F Gomi ${ }^{1,6}$, J Hitomi ${ }^{1,5}$, \\ T Yanagita ${ }^{1,5}$, T Kudo ${ }^{2}$, A Honda ${ }^{1,5}$, Y Mori ${ }^{1,5}$, S Matsuzaki ${ }^{1,5}$, \\ K Imaizumi ${ }^{3}$, A Mayeda ${ }^{\star, 4}$ and M Tohyama ${ }^{1,5}$ \\ 1 Department of Anatomy and Neuroscience, Graduate School of Medicine, \\ Osaka University, Suita, Osaka 565-0871, Japan \\ 2 Department of Clinical Neuroscience, Psychiatry, Graduate School of \\ Medicine, Osaka University, Suita, Osaka 565-0871, Japan \\ 3 Division of Structural Cell Biology, Nara Institute of Science and \\ Technology,Takayama, Ikoma, Nara 630-0101, Japan \\ 4 Department of Biochemistry and Molecular Biology, University of Miami School \\ of Medicine, Miami, FL 33136-1019, USA \\ ${ }^{5}$ CREST, Science and Technology Corporation, Osaka 565-0871, Japan \\ ${ }^{6}$ Department of Ophthalmology, Graduate School of Medicine, Osaka \\ University, Suita, Osaka 565-0871, Japan \\ ${ }^{7}$ Contributed equally to this work. \\ * Corresponding authors: T Katayama, Department of Anatomy and \\ Neuroscience, Graduate School of Medicine, 2-2, Yamada-oka, suita, Osaka \\ University, Suita, Osaka 565-0871, Japan. A Mayeda, Department of \\ Biochemistry and Molecular Biology, University of Miami School of Medicine, \\ 1011 N.W. 15th Street, Miami, FL 33136-1019, USA. \\ E-mail: katayama@anat2.med.Osaka-u.ac.jp; mayeda@miami.edu
}

Received 13.11.02; revised 17.12.02; accepted 18.12.02

Edited by $\mathrm{H}$ Ichijo

\begin{abstract}
The aberrant splicing isoform (PS2V), generated by exon 5 skipping of the Presenilin-2 (PS2) gene transcript, is a diagnostic feature of sporadic Alzheimer's disease (AD). We found PS2V is hypoxia-inducible in human neuroblastoma SK-N-SH cells. We purified a responsible trans-acting factor based on its binding to an exon 5 fragment. The factor was identified as the high mobility group A1a protein (HMGA1a; formerly HMG-I). HMGA1a bound to a specific sequence on exon 5 , located upstream of the $5^{\prime}$ splice site. HMGA1a expression was induced by hypoxia and the protein was accumulated in the nuclear speckles with the endogenous splicing factor SC35. Overexpression of HMGA1a generated PS2V, but PS2V was repressed by cotransfection with the U1 snRNP $70 \mathrm{~K}$ protein that has a strong affinity to HMGA1a. HMGA1a could interfere with U1 snRNP binding to the $5^{\prime}$ splice site and caused exon 5 skipping. HMGA1a levels were significantly increased in the brain tissue from sporadic $A D$ patients. We propose a novel mechanism of sporadic AD that involves HMGA1a-induced aberrant splicing of PS2 premRNA in the absence of any mutations.

Cell Death and Differentiation (2003) 10,698-708. doi:10.1038/ sj.cdd. 4401221
\end{abstract}

Keywords: Alzheimer's disease; HMGA1a; Hypoxia; Presenilin-2; Splicing

Abbreviations: $\mathrm{AD}$, Alzheimer's disease; $\mathrm{A} \beta, \beta$-amyloid; APP, Amyloid-precursor-protein; PS1, Presenilin-1; PS2, Presenilin-2; FTDP-17, Frontotemporal dementia and Parkinsonism linked to chromosome 17; CFTR, cystic fibrosis transmembrane conductance regulator; $\mathrm{PS} 2 \mathrm{~V}$, splicing variant of the $P S 2$ gene that lacks exon 5; HMGA1a, high mobility group protein A1a.; RT-PCR, reverse transcription-polymarase chain reaction; TM, tunicamycin; ER, endoplasmic reticulum; hnRNPA1, heterogeneous ribonucleoprotein A1; RRM, RNA-recognition motif.

\section{Introduction}

Alzheimer's disease $(A D)$ is a neurodegenerative disorder associated with pathological changes in nervous tissue such as severe neuron loss, glial proliferation, extracellular deposition of senile plaques composed of $\beta$-amyloid $(\mathrm{A} \beta)$ and intraneural neurofibrillary tangles (reviewed in Selkoe ${ }^{1}$ ). Mutations in the genes for amyloid-precursor-protein (APP), Presenilin-1 (PS1), and Presenilin-2 (PS2) are known causes for familial AD. ${ }^{2,3}$ Despite extensive research, however, little is known about the causative mechanisms of sporadic $A D$, which accounts for over $90 \%$ of $A D$ cases.

Alternative splicing of precursor mRNA transcripts, or premRNA, is a potent strategy for the regulation of gene expression in eucaryotes. ${ }^{4-6}$ Variation in the selection of the alternative splice sites and/or alternative exons results in the production of different protein isoforms from the same gene, often in response to tissue-specific, physiologically, or developmentally regulated states. The alternative spliced isoforms may have a distinct function, but occasionally they lack proper function altogether. Recently, isoforms with aberrant function have been reported to be associated with certain degenerative disorders. For example, splicing mutants with four-repeat isoforms containing exon 10 of tau gene have been found in frontotemporal dementia and Parkinsonism linked to chromosome 17 (FTDP-17). ${ }^{7}$ Cases of complex cystic fibrosis were reported to be associated with the production of inactive cystic fibrosis transmembrane conductance regulator (CFTR) protein, which is generated by aberrant exon 9 skipping of the coding pre-mRNA. ${ }^{8}$

Previously, two mutant transcripts lacking exons 4 and 9 of the PS1 gene have been identified in familial AD. ${ }^{9,10} \mathrm{We}$ reported the preferential expression of a characteristic splicing variant of the PS2 gene that lacks exon 5 (isoform termed PS2V) in the sporadic AD brain, which is not caused by a mutation of the gene but possibly by a trans-acting factor. ${ }^{11}$ We showed that PS2V protein impaired the signaling pathway of the unfolded protein response, in a manner similar to familial AD-linked PS1 mutant proteins, and caused 
significant increases in the production of $\mathrm{A} \beta$ protein. ${ }^{12}$ Intriguingly, we observed PS2V-encoded aberrant proteins in fragile pyramidal cells of the hippocampal CA1 region and in cells of the cerebral cortex of sporadic AD brains. ${ }^{12,13}$

To elucidate the mechanism of the PS2V isoform generation, we searched for the factor that specifically binds to the exon 5 sequence of PS2 pre-mRNA. The aberrant splicing resulting in the PS2V isoform is hypoxia-inducible in cultured neuroblastoma cells. ${ }^{11}$ We identified a protein that binds to the exon 5 region, and demonstrated that it causes aberrant splicing of the $P S 2$ transcript. The identified protein was a high mobility group protein A1a (HMGA1a, also known as HMG-I formerly), which is a member of the AT-hook protein (HMGA) family. ${ }^{14}$ The HMGA protein family is distinct from HMG-box protein family (includes HMGB and SOX protein groups).

Members of the HMGA protein family participate in many cellular processes, including regulation of inducible gene transcription, integration of retroviruses into chromosomes, and the metastatic progression of cancer cells (reviewed in Reeves. ${ }^{15}$ ) HMGA protein contains three copies of a conserved DNA-binding peptide motif called the 'AT-hook' that preferentially binds to the minor groove AT-rich sequence in DNA, and specifically interacts in vivo with a large number of other proteins, which are often transcription factors.

This is the first report identifying HMGA1a as a pre-mRNAbinding protein that induces aberrant alternative splicing of PS2 pre-mRNA. Here we show evidence of a correlation between the expression of HMGA1a and the etiology of sporadic AD.

\section{Results}

\section{Hypoxia causes PS2V production in neuroblastoma SK-N-SH cells}

We determined the cell types and stress conditions optimized for producing an aberrant splice variant of $P S 2$ gene transcript by reverse transcription-polymerase chain reaction (RT-PCR) as previously described. ${ }^{11,12}$ In sporadic $A D$ brains, a unique shorter product PS2V, which lacked exon 5, was detected along with a major RT-PCR product corresponding to the fulllength PS2 mRNA (Figure 1a). We found that SK-N-SH neuroblastoma cell line also produced a shorter PS2V isoform besides the PS2 product by hypoxia (Figure 1b). In contrast, a

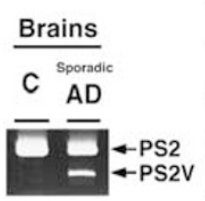

b

$\frac{\text { Cell Lines }}{\frac{\text { Normoxia }}{\text { HeLa 293T SK }} \frac{\text { Hypoxia }}{\text { HeLa 293T SK }} \frac{\mathrm{TM}}{\mathrm{SK}} \frac{\mathrm{A} \beta}{\mathrm{SK}}}$

Figure 1 Detection of normal PS2 transcript and aberrant isoform PS2V in the brain of sporadic AD patient and various cell lines. (a) Total RNA was extracted from a representative sporadic $A D$ patient brain or an age-matched control brain (C). RT-PCR-amplified products were separated on a polyacrylamide gel and visualized by ethidium bromide staining. Arrows indicate the positions of the normal PS2 transcript and the aberrant PS2V transcript (lacking exon 5). (b) Total RNA was extracted from various cell lines subjected to different stresses (see text) and RT-PCR was performed to detect corresponding PS2 and PS2V transcripts same as in (a). Identity of PS2V was verified by cDNA sequencing only the full-length PS2 product was detected in both HeLa and HEK 293T cells by hypoxia. The shorter PS2V isoform was not detected when cells were subjected to other $A D$ related stresses, including exposure to tunicamycin (TM), $A \beta$, or $\mathrm{H}_{2} \mathrm{O}_{2}$ (Figure $1 \mathrm{~b}$; data not shown; Sato et al. ${ }^{11}$ )

\section{Site-specific binding to exon 5 of PS2 pre-mRNA is observed by hypoxia}

Since the PS2V isoform was detected in SK-N-SH cells only by hypoxia, we assumed that a PS2 pre-mRNA-binding factor, which leads to skipping of exon 5 of the PS2 transcript, exists in nuclear extracts from the hypoxic SK-N-SH cells. To detect the PS2 pre-mRNA-binding factor, we performed a premRNA-binding assay by ultraviolet (UV) crosslinking to various ${ }^{35} \mathrm{~S}$-labeled probes derived from PS2 pre-mRNA (Figure $2 a$ and $b$ ). When using mini-PS2 pre-mRNA No. 0 as a probe, the binding activity was clearly demonstrated in nuclear extracts from SK-N-SH cells subjected to hypoxia but not from cells subjected to normoxia, that is, a discrete crosslinked product of $\sim 18 \mathrm{kDa}$ was observed almost exclusively (Figure 2c, arrow). This binding activity was almost fully destroyed by heating the nuclear extracts prior to the assay (data not shown), suggesting that the binding factor is a protein rather than a nucleic acid or lipid. Furthermore, this binding factor bound to the 3' end of exon 5 specifically by hypoxia (Figure $2 d$, No. 5). The strong binding activity of the No. 0 probe was competed by the addition of unlabeled No. 5 probe, but not by the addition of other unlabeled probes (Figure 2e, Nos. 1-4).

a

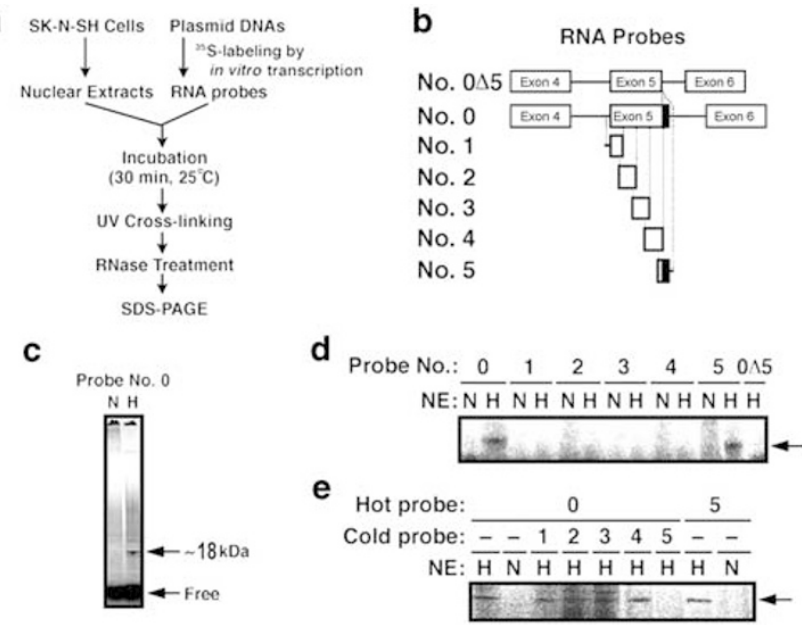

Figure 2 UV crosslinking assays of PS2 exon 5-binding protein. (a) Experimental scheme of pre-mRNA binding assays by UV crosslinking. See Materials and Methods in detail. (b) Schematic representations of the seven RNA probes used (drawn not to scale). Boxes and solid lines represent exons and introns, respectively. The black shading indicates the detected binding site. All probes were uniformly ${ }^{35}$ S-labeled by in vitro transcription as described in Materials and Methods. (c and d) Nuclear extracts (NE) from SK-N-SH cells in normoxia $(\mathrm{N})$ or hypoxia $(\mathrm{H})$ were analyzed in UV crosslinking assays with each of the ${ }^{35}$ S-labeled probes and subjected to SDS-PAGE (10-20\% gradient gel). Arrow indicates the position of HMGA1a protein $(\sim 18 \mathrm{kDa})$. (e) Nuclear extracts (NE) from SK-N-SH cells in normoxia (N) or hypoxia $(\mathrm{H})$ were pre-incubated with 100 -fold excess of the indicated nonradioactive (Cold) probes. The pre-incubated reactions were used for the UV crosslinking assay with ${ }^{35} \mathrm{~S}$-labeled probe (Hot), and subjected to SDS-PAGE (15\% gel). Arrow indicates the position of HMGA1a protein 
This binding activity is site specific since the deletion mutant of No. 0 that lacks the sequence of No. 5 did not bind (Figure $2 b$ and $\mathrm{d}$, No. $0 \Delta 5$ ). We analyzed the time course of UV crosslinking with No. 5 probe in nuclear extracts from cells under either normoxia or hypoxia. Increased binding activity to the probe was observed in the nuclear extracts from cells subjected to hypoxia, but not normoxia, during 16-21 h after induction, and this binding activity lasted for at least another $24 \mathrm{~h}$ (data not shown). We conclude that the site-specific binding of an unknown $\sim 18 \mathrm{kDa}$ protein to PS2 pre-mRNA is specifically induced by hypoxia.

\section{HMGA1a is a specific exon 5-binding factor}

The factor that specifically binds to No. 5 probe was purified from nuclear extracts derived from SK-N-SH cells subjected to hypoxic stress (Figure $3 a$ and $b$ ). Partially purified fractions II and III that show strong activity were obtained by ammonium sulfate precipitation followed by ion-exchange chromatography on a DEAE column (Figure 3c). Further purification on a short RNA-affinity column, using probe No. 5, yielded a fraction with a higher specific activity (Figure 3c, fraction IV), albeit the protein was not yet homogeneous (Figure 3b, fraction IV). Finally, reversed-phase chromatography was employed to purify this fraction to near homogeneity (fraction $\mathrm{V}$, arrow). The lower specific activity in fraction $\mathrm{V}$ may be because of the partial denaturation by the organic solvents used (Figure 3c, fraction V; see Materials and Methods).

We obtained partial amino-acid sequence of the polypeptide isolated in the fraction $\mathrm{V}$, and compared it with known proteins and predicted proteins from cDNA sequences in the databases (see Materials and Methods). This search resulted in a perfect match to the human HMGA1a (also known as HMG-I formerly), but not to HMGA1b (also known as HMG-Y formerly), which is a splice variant of HMGA1 gene. ${ }^{16}$
To determine whether HMGA1a is sufficient to explain the observed specific $\sim 18 \mathrm{kDa}$ UV crosslinked signal, immunodepletion of HMGA1a from the nuclear extracts of hypoxic SK$\mathrm{N}-\mathrm{SH}$ cells was performed. Immunoblotting analysis revealed $\sim 81 \%$ depletion of HMGA1a, and the depleted extracts showed significant loss in binding to No. 5 probe (data not shown). The specific binding activity observed by UV crosslinking was also verified by electrophoretic mobility shift assays. We observed much stronger shifted complex using nuclear extracts from hypoxia-exposed SK-N-SH cells than that from normoxia-conditioned cells, and furthermore, the mobility of this complex was supershifted by pretreatment with anti-HMGA1 antibody in a concentration-dependent manner (data not shown). Taken together, we conclude that HMGA1a is the bona fide protein factor responsible for the specific binding to probe No. 5 .

\section{HMGA1a binding is sequence specific}

There are two repeated homologous sequences in the 3' terminal of PS2 exon 5, which are included in probe No. 5 (Figure 3d, No. 5, highlighted with pink). To examine whether HMGA1a actually recognizes these tandem sequences, we prepared six more short RNA probes (Figure 3d, Nos. 6-11) for the UV crosslinking assays as before (Figure 3e). In contrast to the strong binding activity to probe No. 5 , we could not detect significant binding to probe No. 6, which is upstream of the tandem sequences. Strong binding signals were also obtained with probes that consist of only two tandem sequences, regardless of UACC spacer found in the original pre-mRNA (Nos. 7 and 10). Importantly, the binding was abolished when a point mutation ( $C$ to $A$ ) was introduced into each of the tandem sequences (No. 8). The binding activities were retained with probes that include either upstream or downstream tandem sequence (Nos. 9 and 11). a

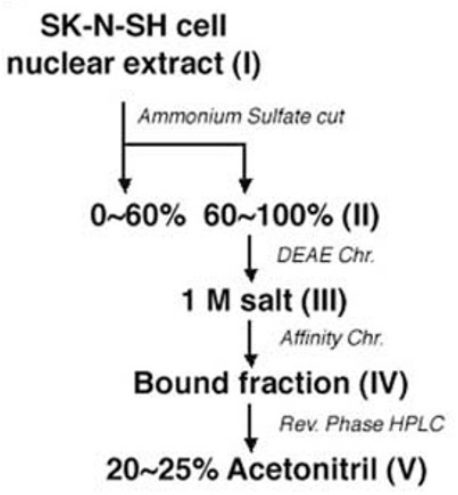

b

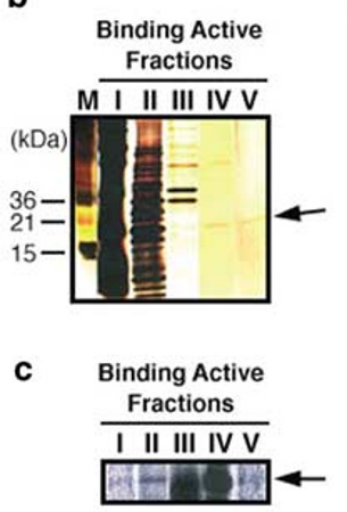

d RNA Probes HMGA1a Binding Sites

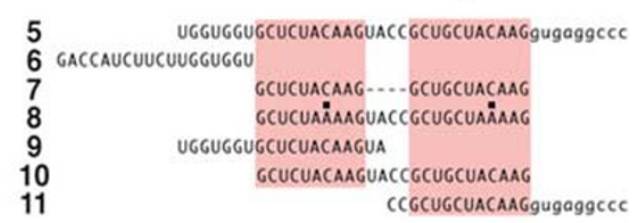

e

NE: $\mathbf{N}$

$\mathrm{H}$

Probe No.: $\overline{5} \overline{5} 678891011$

Figure 3 Purification and characterization of human HMGA1a. (a) The purification profile of the specific binding activity to No. 5 probe from nuclear extracts of hypoxiainduced SK-N-SH cells. The methods of purification are indicated in italics. Individual fractions are designated with Roman numerals. (b) Protein analysis of each fraction (25 $\mu$ l/fraction) on 15\% SDS-PAGE followed by silver staining. M: molecular weight (kDa) markers. (c) UV crosslinking assays (with No. 5 probe) to evaluate binding activity of each purified fraction (15 $\mu /$ /fraction). (d) Sequences of the RNA probes (Nos. 5-11). Exons and introns are shown in uppercase and lowercase, respectively. The homologous tandem sequences are shaded in pink boxes. (e) UV crosslinking assay with the seven RNA probes shown in (d). See Figure $2 c$ for the abbreviations. Arrow indicates the position of HMGA1a protein 
These results demonstrate that either one of these two tandem sequences is sufficient for HMGA1a binding to the PS2 pre-mRNA.

\section{The expression of HMGA1a is induced by hypoxia}

To examine whether the binding activity induced by hypoxia is dependent on HMGA1a expression in vivo, we analyzed its expression at both the message and the protein product level. Northern blotting analyses showed that mRNA levels of HMGA1a are gradually increased (maximum 220\% of the normoxia) in SK-N-SH cells expressing PS2V by hypoxia (Figure 4a, left panel). However, in hypoxia-exposed HEK 293T cells (middle panel) or tunicamycin-treated SK-N-SH cells (right panel), where PS2V was not induced, no significant increase of HMGA1a mRNA levels was observed. Immunoblotting analyses using anti-HMGA1 antibody detected higher levels of HMGA1a protein in nuclear extracts of SK-N-SH cells under hypoxia compared to those cultured under normoxia (Figure 4b, left panel, arrow). HMGA1a protein was barely detected in HEK 293T cells exposed to hypoxia (middle panel), and very low levels in tunicamycin-treated SK-N-SH cells (right panel). We confirmed that there was no difference in the induction of HSP70, as a positive control, in each cell lines (data not shown).

\section{HMGA1a colocalizes with an authentic splicing factor by hypoxia}

To determine the subcellular localization of HMGA1 proteins, we exposed SK-N-SH cell cultures in hypoxia for $21 \mathrm{~h}$ and detected the presence of endogenous HMGA1 protein by immunofluorescent microscopy with anti-HMGA1 antibody. To indicate the presence and location of authentic splicing factors, an antibody against SR protein SC35, which shows typical nuclear speckle localization, was used as a standard. ${ }^{17}$ In the normal conditions, HMGA1 localized mainly to nuclei of SK-N-SH cells together with weak and diffuse immunoreactivity in the cytoplasm, and it did not well colocalize with SC35 in the nuclear speckles (Figure 4c, 'Normoxia'). However, in hypoxia-exposed SK-N-SH cells, strong immunoreactivity was clearly observed in the nuclear speckles that colocalized with SC35, while its cytoplasmic distribution was decreased (Figure 4c, 'Hypoxia'). We conclude that induced HMGA1 accumulated in the nuclear speckles in hypoxic SK-N-SH cells - which are storage or assemble sites for splicing components (reviewed in Misteli and Spector ${ }^{18}$ ).

\section{PS2V is produced by the overexpression of HMGA1a}

To investigate whether the skipping of exon 5 of the PS2 transcript in hypoxia-exposed SK-N-SH cells is because of the action of HMGA1a, we transiently overexpressed HMGA1a in the cultured cells and analyzed the splicing of PS2 pre-mRNA in vivo.

Markedly higher levels of HMGA1a protein expression were observed in nuclear extracts from HMGA1a-transfected SK$\mathrm{N}-\mathrm{SH}$ and HEK 293T cells compared to mock-transfected a

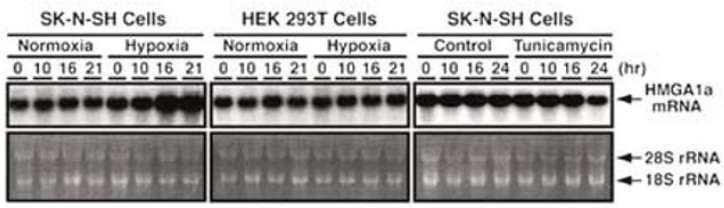

b

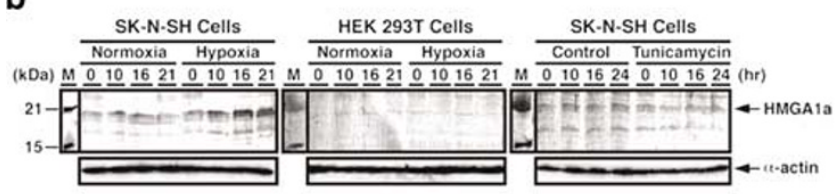

C

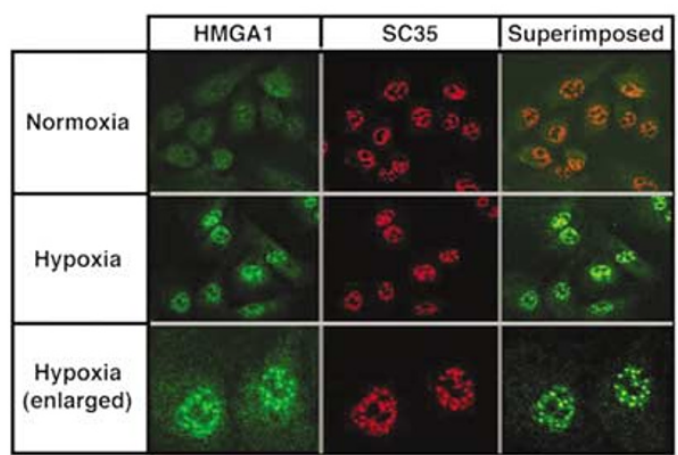

Figure 4 Effects of various stresses on the expression of HMGA1a mRNA and protein in cultured cell lines. (a) Each cell line was exposed to normoxia or hypoxia and then harvested at the indicated time (left and middle panels). TMtreated SK-N-SH cells were recovered at the indicated times after the treatment (right panel). Total RNAs were separated by formaldehyde-formamide-agarose gel electrophoresis and subjected to Northern blotting assays using a ${ }^{32} \mathrm{P}$-labeled HMGA1a cDNA probe. Detection of rRNAs by denaturing PAGE is shown (lower panel) as an internal control. Arrows show the positions of the indicated RNAs. (b) Nuclear fractions from normoxia or hypoxia were separated by SDS-PAGE and subjected to the immunoblotting assays using an anti-HMGA1 antibody. Expression levels of $\alpha$-actin were used as an internal control (lower panel). Arrow indicates the positions of the HMGA1a (upper panel) and $\alpha$-actin (lower panel). (c) Effects of hypoxia on the subcellular localization of endogenous HMGA1 protein in SK-N-SH cells. SK-N-SH cells were exposed to normoxia or hypoxia for $21 \mathrm{~h}$. Cells were double-immunostained with anti-SC35 antibody and antiHMGA1, followed by staining with Сy3- and FITC-conjugated secondary antibodies, respectively, and analyzed by immunofluorescence microscopy. Endogenous HMGA1 (green color) and SC35 (red color) images were superimposed and the yellow-green color indicates colocalization of the two proteins in nuclear speckles

cells (Figure 5a). By RT-PCR assays of total RNA from mock-transfected SK-N-SH cells, the product corresponding to the full-length PS2 mRNA could be detected (Figure $5 \mathrm{~b}$, left panel). In contrast, when using total RNA from HMGA1atransfected cells, RT-PCR produced a shorter product in addition to the full-length product. The amount of the shorter product detected was proportional to the amount of transfected-HMGA1a cDNA (left panel). Direct DNA sequence analysis of the shorter RT-PCR product identified it as PS2V isoform that lacks exon 5. In contrast, weak induction of PS2V was observed in SK-N-SH cells transiently transfected with HMGA1b (left panel). By overexpression of HMGA1a, PS2V was also detected in non-neuronal HEK 293T cells (Figure 5b, right panel), even though PS2V could not be induced in this cell line by hypoxia (Figure 1b). These results suggest that the production of PS2V is solely controlled through the induction 
a $\mathrm{SK}-\mathrm{N}-\mathrm{SH}$ Cells

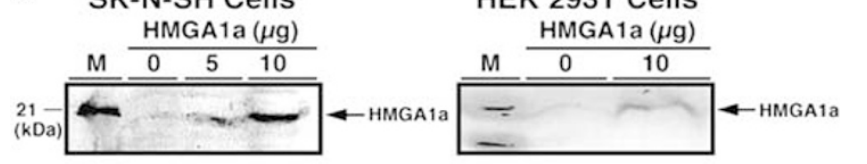

b

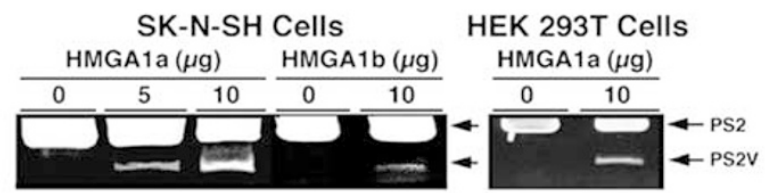

C

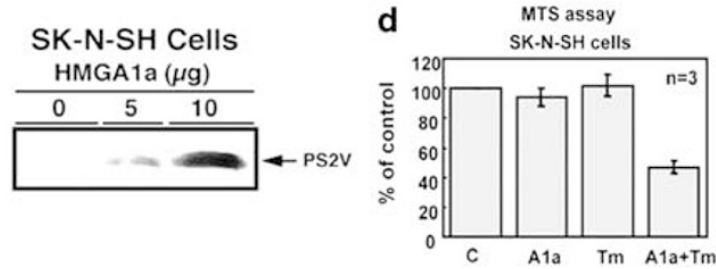

Figure 5 Effects of overexpression of HMGA1 on PS2 pre-mRNA splicing and cell death in cultured cells. (a) Overexpression of HMGA1 protein detected by immunoblotting assay. The indicated cell lines were transiently transfected with HMGA1 and cells were harvested $24 \mathrm{~h}$ after transfection. The nuclear extracts were separated by SDS-PAGE and assayed by immunoblotting with anti-HMGA1 antibody. Arrows indicate the position of the HMGA1a protein. (b) Generation of aberrant PS2V mRNA was detected by RT-PCR. Transient transfection was performed as in (a) and total RNA from harvested cells was analyzed by RT-PCR with specific primers. Amplified products were separated on a PAGE and visualized with ethidium bromide. Arrows indicate the positions of the normal PS2 mRNA (upper) and aberrant PS2V isoform (lower). (c) Generation of PS2V protein detected by immunoblotting analysis. Transient transfection was performed as in (a) and PS2V protein in nuclear extracts from the transfected cells were immunoprecipitated by using anti-PS2N antibody (against PS2 and PS2V), followed by immunoblotting assay using PS2V-specific anti-SSMAG antibody (SSMAG is a PS2V specific C-terminal peptide). (d) The effects of HMGA1 expression on SK-N-SH cell viability under TM stress were evaluated by cell death (MTS) assay. SK-N-SH cells were transfected with or without HMGA1a (A1a), followed by treatment with or without TM. Results are expressed as percent $(\%)$ of living cells in control (neither HMGA1a transfection nor tunicamycin treatment). The means $+/-$ S.E. of 5 replicates per group were plotted on a histogram

of HMGA1a regardless of cell type. This observation is consistent with the fact that the induction of HMGA1a protein by hypoxia occurs only in neuronal SK-N-SH cell lines (Figure $4 \mathrm{~b})$. Indeed, we confirmed that the PS2V protein product was induced in nuclear extracts from HMGA1a-transfected SK-N$\mathrm{SH}$ cells in a dose-dependent manner (Figure 5c). Finally, cells overexpressing HMGA1a were more sensitive to endoplasmic reticulum (ER) stress (Figure $5 d$ ), as observed in the cells expressing PS2V. ${ }^{12}$

\section{HMGA1a binds U1 snRNP via direct interaction with the U1-70K protein}

The functional binding of U1 snRNP to the $5^{\prime}$ splice site is essential in an early step of splicing (reviewed in Kramer, ${ }^{19}$ Will and Lührmann, ${ }^{20}$ and Burge et al. ${ }^{21}$ ). It was demonstrated that protein interactions between U1-70K, an integral protein component, and SR protein SF2/ASF enhances the binding of U1 snRNP to the $5^{\prime}$ splice site. ${ }^{22}$ SR protein was also shown to interact with both $\mathrm{U} 1-70 \mathrm{~K}$ protein and the $35 \mathrm{kDa}$ subunit of the splicing factor U2AF (U2AF ${ }^{35}$ ), which binds to the $3^{\prime}$ splice site, and is suggested to function in correct splice site selection by bridging between components bound to the $5^{\prime}$ and $3^{\prime}$ splice sites. ${ }^{23}$

By immunoprecipitation with either anti-U1-70K or antiHMGA1 antibody, we found that HMGA1a has a strong affinity to U1-70K protein in hypoxia-induced SK-N-SH cells, but not in normoxia-conditioned cells in which HMGA1a was not expressed much (Figure $6 \mathrm{a}$, left panels, $\mathrm{N}$ and $\mathrm{H}$ lanes). This immunoprecipitation was because of a direct protein interaction between U1-70K and HMGA1a, since U1-70K and HMGA1a were also coimmunoprecipitated after micrococcal nuclease treatment (left panels, $\mathrm{H}+\mathrm{M}$ ). Other U1 snRNP proteins $A$ and $C$ were also immunoprecipitated with antiHMGA1; however, these interactions were abolished by nuclease treatment, and thus they are nonspecific or indirect interactions mediated by the RNA (data not shown). The levels of these U1 snRNP proteins were not altered by hypoxia (right panels).

To prove anti-HMGA1a antibody immunoprecipitated majority of intact U1 snRNP, but not free U1-70K protein, snRNA moiety of the immunoprecipitate was analyzed by denaturing PAGE (Figure 6b). The discrete U1 snRNA (165nt) was observed in the immunoprecipitate with anti-HMGA1 antibody in hypoxia-induced cells (arrow), and the amount of U1 snRNA is equivalent as control precipitate with anti-U1-70K antibody (both in normoxia and hypoxia cells).

\section{HMGA1a may interfere with U1 snRNP binding to $5^{\prime}$ splice site}

To investigate the effect of binding between HMGA1a and U170K proteins, splicing of PS2 pre-mRNA was analyzed in vivo under conditions of U1-70K overexpression. The production of either HMGA1a-induced or hypoxia-induced PS2V isoform in SK-N-SH cells was clearly repressed by cotransfection of U1-70K cDNA in a dose-dependent manner, but not by cotransfection of another U1 snRNP protein cDNA, U1-A (Figure 6c). The expression of HMGA1a protein itself was not altered by cotransfection of either U1-70K or U1-A cDNA (lower panels). We demonstrated that the HMGA1a binding site of PS2 pre-mRNA exists upstream from the $5^{\prime}$ splice of exon 5. Therefore, it is plausible that the strong HMGA1a affinity to U1-70K tethers U1 snRNP to a site upstream from the $5^{\prime}$ splice site and interferes with proper binding of $U 1$ snRNP to the $5^{\prime}$ splice site (Figure $6 \mathrm{~d}$, middle scheme). Overexpressed U1-70K, which is trapped by HMGA1a, could release U1 snRNP allowing proper U1 snRNP binding to the $5^{\prime}$ splice site (lower scheme). Since $5^{\prime}$ splice site recognition of an internal exon is an important determinant for its inclusion in the spliced mRNA (reviewed in Berget $^{24}$ ), the perturbed binding of U1 snRNP could inactivate the $5^{\prime}$ splice site and caused exon 5 skipping.

\section{Increased levels of HMGA1a protein were observed in brains of sporadic AD patients}

Since HMGA1a protein is responsible for the aberrant splicing, or exon 5 skipping, of PS2 pre-mRNA, we suppose that there may be a higher level of HMGA1a expression in 
a

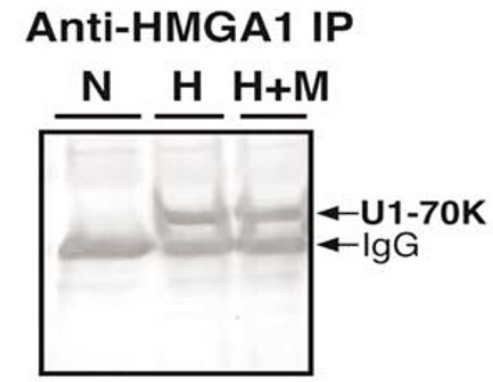

\section{Anti-70K IP}

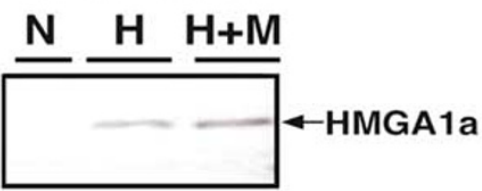

b
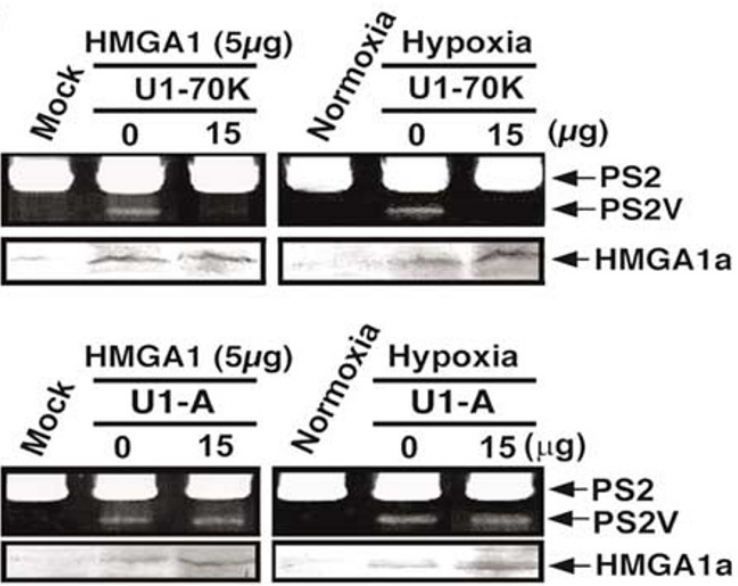

Before IP

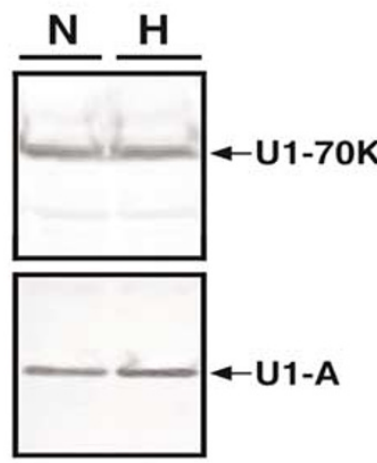

b

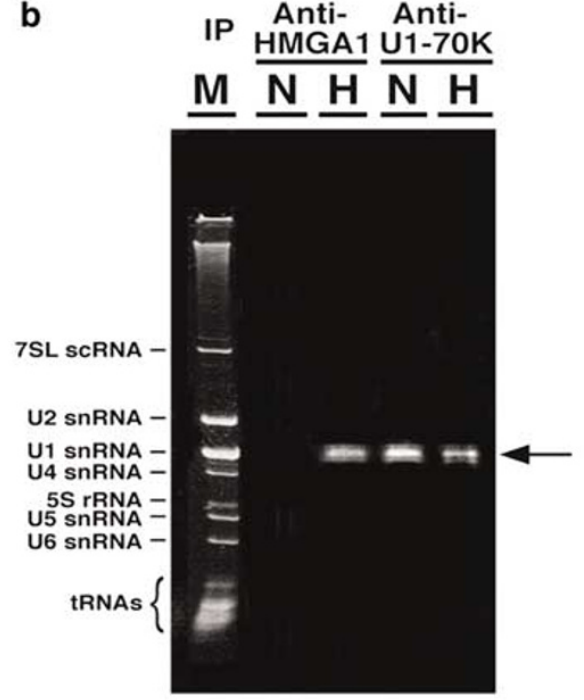

d

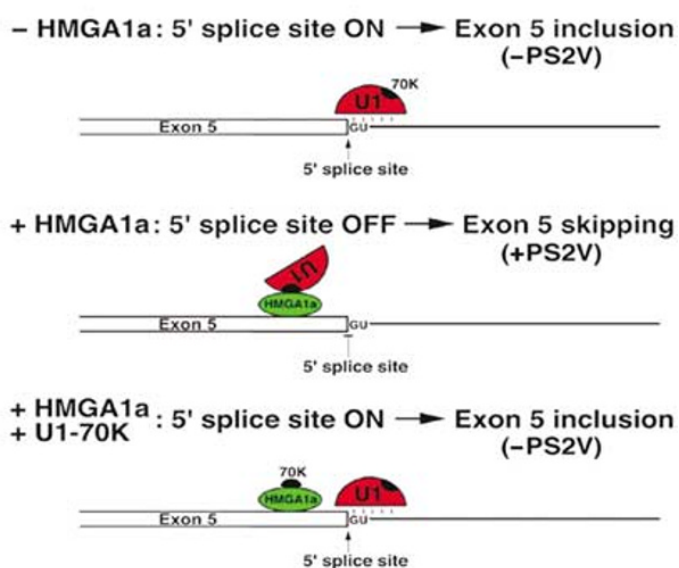

Figure 6 Interaction of HMGA1a and U1-70K proteins and the effect of U1-70K overexpression on PS2 pre-mRNA splicing in vivo. (a) Coimmunoprecipitation of HMGA1a and U1-70K proteins detected with either anti-HMGA1 or anti-U1-70K antibody (left two panels). The nuclear fractions from normoxia (N)- or hypoxia (H)exposed SK-N-SH cells were prepared. A portion of the hypoxia-exposed nuclear fractions was treated with micrococcal nuclease $(\mathrm{H}+\mathrm{M})$. These nuclear fractions were immunoprecipitated by an anti-HMGA1 antibody, followed by immunoblotting assay using an anti-U1-70K antibody (left top panel). The same nuclear fractions were immunoprecipitated by an anti-U1-70K antibody, followed by immunoblotting assay using an anti-HMGA1 antibody (left bottom panel). The endogenous levels of U1-70K and U1A proteins in the same nuclear fractions $(\mathrm{N}$ and $\mathrm{H}$ ) were examined by immunoblotting with anti-U1-70K and anti-U1A antibodies, respectively (right two panels). Arrows show the positions of the indicated proteins. (b) Detection of discrete U1 snRNA in the immunoprecipitates. SK-N-SH cell nuclear fractions (N and H) were immunoprecipitated by an anti-HMGA1 or anti-U1-70K antibody, followed by phenol extraction and ethanol precipitation. Precipitated RNA was separated on denatured PAGE followed by ethidium bromide staining. RNA was also extracted directly from SK-N-SH cell nuclear extract and used as a marker (M). Each of the identified RNA species were indicated on the left. Arrow indicates the position of U1 snRNA (165 nt). (c) Effects of transient U1-70K or U1A overexpression on the generation of the PS2V isoform. PS2V was induced either by the HMGA1 transfection (left two panels) or hypoxia (right two panels). The level of induced HMGA1a protein (arrow) was monitored by immunoblotting (attached lower to each panel). Arrows indicate the positions of the PS2 and PS2V mRNAs. (d) The model for the mechanism of HMGA1ainduced aberrant exon 5 skipping. Hypoxia-induced HMGA1a protein binds to the conserved HMGA1a-binding site (upstream of the $5^{\prime}$ splice of the middle exon 5). U1 snRNP is tethered by binding between HMGA1a and U1-70K component, which interferes with proper binding of U1 snRNP to the $5^{\prime}$ splice site. The disabled $5^{\prime}$ splice site causes exon 5 skipping between upstream exon 4 and downstream exon 6 (PS2V production). Overexpression of free U1-70K, which binds to HMGA1a, allows proper U1 snRNP allocation at the 5' splice site, and exon 5 inclusion is restored (no PS2V production)

sporadic $A D$ patient brains than in normal brains. We examined the levels of HMGA1 proteins in the brain tissue of sporadic AD patients (Figure 7a). Immunoblotting with anti-HMGA1 antibody showed that the levels of both HMGA1a and HMGA1b were increased in total lysates and nuclear fractions from the hippocampus of sporadic $A D$ patients, compared with those of age-matched controls (left and right panels). Only low levels of HMGA1 proteins were observed in cytosolic fractions from the hippocampus of both sporadic AD patients and age-matched controls (middle panel), which is consistent with the fact that the majority of HMGA1 localizes to the nuclei (Figure 4c).

Furthermore, immunohistochemical analysis was performed to determine the region of the hippocampus where HMGA1 is localized. HMGA1 protein was markedly accumulated in the pyramidal cell layer in the hippocampal CA1 region 


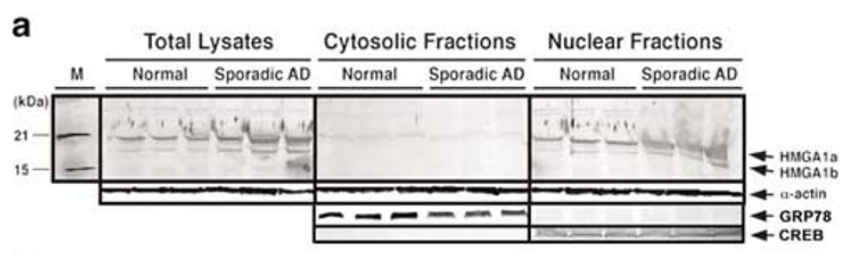

b

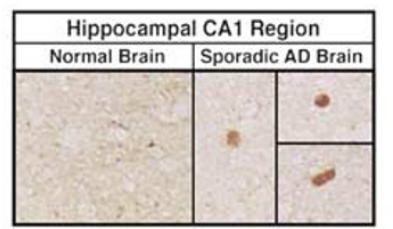

Figure 7 Expression of HMGA1 protein in the brain tissue of sporadic $A D$ patients. (a) Total lysates, cytosolic fractions, and nuclear fractions were prepared from the hippocampus tissues of three different sporadic AD patients and age-matched controls. These fractions were separated by SDS-PAGE and assayed by immunoblotting with an anti-HMGA1 antibody. Expression levels of GRP78 and CREB were used as a fraction marker (see Figure $4 b$ for the expression of $\alpha$-actin as an internal control (middle panel) lower two panels). Arrows indicate the positions of the HMGA1a and HMGA1b proteins. Quantitative data from 10 different sporadic $A D$ patients as percentages of controls were obtained as follows (mean \pm S.E.): $100 \pm 13.5$ (nuclear fraction control) versus $141.6 \pm 18.5$ (nuclear fraction of sporadic AD patients). (b) Hippocampus tissues from controls and sporadic AD patients were sectioned at a thickness of $10 \mu \mathrm{m}$ and HMGA1 proteins were immunohistochemically detected (five patients were examined)

in sporadic AD patients compared to controls that include nonAD patients (Figure $7 \mathrm{~b}$; data not shown).

\section{Discussion}

\section{The role of aberrant PS2V protein in sporadic AD}

Previously, we found that the PS2V isoform was expressed specifically in brain tissues of sporadic AD patients. PS2V mRNA, lacking exon 5, encodes the amino-terminal portion of PS2, which contains residues from Met 1 through Leu 119 followed by 5 additional amino acids (SSMAG) at its Cterminus. Although the amount of aberrant PS2V mRNA is less than full-length PSV mRNA, the PS2V protein was detected with PS2V-specific antibody (anti-SSMAG) in neuropathologically affected neurons of the hippocampal CA1 region and temporal cortex of all sporadic $A D$ patients tested (21 cases; data not shown). Furthermore, we have reported that the PS2V protein indeed impaired the signaling pathway of the unfolded-protein response, as was seen with familial AD-linked PS1 mutants, ${ }^{25}$ and caused increases in susceptibility to various ER stress, as well as significant increases in the production of both amyloid $\beta_{1-40}$ and $\beta_{1-42}$, which is a shared characteristic of AD patients. ${ }^{12}$ Although the detailed mechanism of PS2V-triggered $A D$ remains to be elucidated, PS2V may be a diagnostic marker in the neuropathology of sporadic AD. In fact, our previous report indicated that PS2V protein was not detected in FAD brains and in other disease control brains (Parkinson's disease, Huntington's disease, ALS, Machado-Joseph disease, etc.). ${ }^{12}$ It was recently reported that variant protein isoforms in neurodegenerative diseases might either lack function or confer novel characteristics on their cellular environment. $^{7,9,10,26}$

\section{Clinical significance of hypoxia in sporadic AD}

In this report, we demonstrated that HMGA1a is a mediator of aberrant PS2 pre-mRNA splicing, or production of deleterious PS2V protein. Consistently, we observed increased steadystate levels of HMGA1 in the brains of sporadic AD patients. In our experiments, HMGA1 was hypoxia-inducible only in a neuronal cell line. It was reported that microinfarction is closely correlated with a history of AD patients (reviewed in Kelaria $^{27}$ ). Furthermore, at acute stage in cerebral infarct in the area of middle cerebral artery, PS2V was detected in the penumbra region around the ischemic core (personal communication). Therefore, sustained hypoxia caused by microinfarction in the brain could be one of the necessary, although not sufficient, triggers to induce HMGA1a-mediated production of aberrant PS2V isoform in sporadic AD patients.

\section{HMGA1a as a sequence-specific RNA-binding protein}

Previously, it was shown that HMGA1 plays an essential role in the assembly and function of the enhanceosome of the human interferon- $\beta$ gene. ${ }^{28,29}$ It binds to three DNA sites within the enhancer, modulates DNA structure, and promotes cooperative binding of transcription factors. Our results presented in this paper, however, provide the first experimental evidence that HMGA1a binds to RNA in a sequencespecific manner. By transfection of 2'-O-methyl RNA that contains an HMGA1a-binding sequence, the generation of PS2V mRNA was reduced in SK-N-SH cells under hypoxia, and the reduction was dependent on the dose of the $2^{\prime}-O$ methyl RNA added (unpublished results). To prove whether this sequence-specific binding of HMGA1a is required for its splicing modulation activity, in vitro splicing analysis is underway with heterologous model $\beta$-globin pre-mRNA, in which the HMGA1a-binding sequence was inserted. So far, we could not find any other genes containing sequences homologous to these tandem HMGA1-binding sites by database homology searches. If this is the case, it suggests that HMGA1-binding site is a signal sequence for specific inducible splicing, responsible for the generation of the PS2V isoform in sporadic AD.

\section{HMGA1a: a novel splicing modulator that is distinct from other known factors}

It was reported that SR proteins and heterogeneous ribonucleoprotein (hnRNP) A1 antagonistically promote exon inclusion/skipping type of alternative splicing in vitro and in vivo. ${ }^{30-}$ ${ }^{32}$ These splicing factors possess an RNA-recognition motif (RRM) in the $\mathrm{N}$-terminus and have characteristic amino-acid sequences that are arginine-serine rich (RS domain) or glycine-rich ( $G$ domain) in the $\mathrm{C}$-terminus, respectively (reviewed in Birney et al. ${ }^{33}$ and $\mathrm{Fu}^{34}$ ). Although HMGA1a induces aberrant exon 5 skipping of PS2 pre-mRNA in vivo, its structural features are distinct from these splicing regulators. HMGA1 proteins possess three AT-hook DNA-binding domains flanked by a serine-rich and a glutamic acid-rich region in its $\mathrm{N}$ - and C-termini, respectively, and lack the RRM and 
other characteristic motifs found in these splicing factors ${ }^{16}$ (reviewed in Reeves ${ }^{15}$ ).

The $5^{\prime}$ splice site inhibitory mechanism of HMGA1a is rather reminiscent of the fruit fly (Drosophila melanogaster) $\mathrm{P}$ element somatic inhibitor (PSI) that specifically binds U1-70K protein and inhibits the corresponding $5^{\prime}$ splice site of $\mathrm{P}$ element pre-mRNA. ${ }^{35}$ However, there is neither homology between HMGA1a and PSI (KH domain splicing factor) proteins nor similarity in their target RNA sequences.

We found that the hypoxia-induced HMGA1 protein markedly accumulated in the nuclear speckles, consistent with its function as a splicing modulator. Previously, it was reported that HMGA1 proteins are mainly localized to heterochromatin masses in actively growing 3T3 fibroblasts, whereas in quiescent cells, they are more diffusely distributed. ${ }^{36}$ Therefore, an important part of the splicing modulation function of HMGA1a in SK-N-SH cells may depend on its timely induction, triggered by hypoxic stimulation, which leads to its functional localization in nuclei. Considering all these features, HMGA1a appears to be a novel substrate-specific splicing modulator rather than a general alternative splicing factor.

In summary, we propose a novel mechanism for the development of sporadic AD cases involving induced aberrant splicing of a particular gene in the absence of any mutations. We demonstrated that HMGA1a is a key factor that binds to PS2 pre-mRNA and causes its aberrant splicing that may be an initial trigger leading to neuronal cell death in sporadic AD. Our mechanistic insight is likely to have a considerable impact on the therapy and prevention of sporadic AD.

\section{Materials and Methods}

\section{Cell culture, hypoxic stimulation, and transient transfections}

Cell culture, hypoxic stimulation, and transient transfections were performed as previously described. ${ }^{11,12}$ Transient transfections of various expression plasmids were carried out using LipofectAmine (Gibco BRL). The full-length cDNAs of HMGA1a, HMGA1b, and U1-70K were amplified by RT-PCR with attached BamHI and EcoRI sites, and subcloned into pcDNA3(+) vector (Invitrogen) between corresponding restriction enzyme sites. U1-A expression plasmid $^{37}$ was a generous gift from $\mathrm{Dr} S$ Gunderson.

\section{Preparation of total RNA and RT-PCR}

Preparation of total RNA from neuroblastoma SK-N-SH cells, HEK 293T cells, and HeLa cells, and the RT-PCR analyses were performed as previously described. ${ }^{11}$ Reverse transcription was carried out using Moloney murine leukemia virus (M-MLV) reverse transcriptase (Promega). PCR conditions used were as previously described. ${ }^{11}$ Experiments were repeated at least four times using separate cell cultures and all gave consistent results.

\section{Preparation of nuclear extracts, cytosolic fractions and nuclear fraction}

Nuclear extracts from cultured cell lines, and their nuclear and cytosolic fractions were prepared as described ${ }^{38}$ with minor modifications. ${ }^{39-41}$

\section{Construction of plasmids}

The PS2 mini-gene, including from exons 4 to 6 with two introns, was constructed by one or more rounds of overlap-extension PCR with two primers (No. 0a, 5'-TCTGATATCAGAAGCCAGGAGAACGAGGAGGACGG$3^{\prime}$ No. 0b, 5'-TCTGAATTCCCAAGGTAGATATAGGTGAAGAGG-3'; PS2 sequence is underlined) followed by subcloning between EcoRV and EcoRI sites of pcDNA3(-) vector (Invitrogen). DNA templates containing each fragment of PS2 exon 5 were prepared by DNA annealing of two complementary synthetic DNAs described as follows (PS2 sequence is underlined):

Nos. 1a/b, 5'-TCTGGATCCTGCCTTCTCCCTCAGCATCTACACGACATTCACTGAGGACACGAATTCAGA-3' / 3'-AGACCTAGGACGGAAGAGGGAGTCGTAGATGTGCTGTAAGTGACTCCTGTGCTTAAGTCT-5'; Nos.2a/b, 5'-TCTGGATCCTGAGGACACACCCTCGGTGGGCCAGCGCCTCCTCAACTCCGTGAATTCAGA-3' / 3'-AGACCTAGGACTCCTGTGTGGGAGCCACCCGGTCGCGGAGGAGTTGAGGCACTTAAGTCT5'; Nos. 3a/b, 5'-TCTGGATCCCAACTCCGTGCTGAACACCCTCATCATGATCAGCGTCATCGTGAATTCAGA-3' / 3'-AGACCTAGGGTTGAGGCACGACTTGTGGGAGTAGTACTAGTCGCAGTAGCACTTAAGTCT-5'; Nos. 4a/b, 5'-CTCGGATCCTGATCAGCGTCATCGTGGTTATGACCATCTTCTTGGTGGTGCGAATTCGAG-3' / 3'-GAGCCTAGGACTAGTCGCAGTAGCACCAATACTGGTAGAAGAACCACCACGCTTAAGCTC-5'; Nos. 5a/b, 5'-TCTGATCCTGGTGGTGCTCTACAAGTACCGCTGCTACAAGGTGAGGCCCTGAATTCAGA-3' / 3'-AGACCTAGGACCACCACGAGATGTTCATGGCGACGATGTTCCACTCCGGGACTTAAGTCT-5'; Nos. 6a/b, 5'-GATCCGACCATCTTCTTGGTGGTG-3'/3'-GGCTGGTAGAAGAACCACCACTTAA-5'; Nos. 7a/b, 5'-GATCCGCTCTACAAGGCTGCTACAAGG-3'/3'-GGCGAGATGTTCCGACGATGTTCCTTAA-5'; Nos. 8a/b, $5^{\prime}$-GATCCGCTCTAAAAGTACCGCTGCTAAAAGG-3'/3'GGCGACATTTTCATGGCGACGATGTTCC-5'; Nos. 9a/b, 5'-TCTGGATCCTGGTGGTGCTCTACAAGTAGAATTCAGA-3'/3'-AGACCTAGGACCACCACGAGATGTTCATCTTAAGTCT-5'; Nos. 10a/b, 5'-TCTGGATCCGCTCTACAAGTACCGCTGCTACAAGGAATTCAGA-3'/3'-AGACCTAGGCGAGATGTTCATGGCGACGATGTTCCTTAAGTCT-5'; Nos. 11a/ b, 5'-TCTGGATCCCCGCTGCTACAAGGTGAGGCCCTGAATTCAGA-3'/ 3'-AGACCTAGGGGCGACGATGTTCCACTCCGGGACTTAAGTCT-5'

Annealed DNA products were subcloned between BamHI and EcoRI sites of the pcDNA3 $(+)$ vector (Invitrogen). DNA sequences of all constructs were verified by automated DNA sequencing (Model 373; Applied Biosystem).

\section{Preparation of RNA probes}

RNA probes were prepared by in vitro transcription with DNA template constructs (including fragments of PS2) in pcDNA3 vectors (Invitrogen). Each template plasmid, linearized with EcoRl, was incubated for $1 \mathrm{~h}$ at $37^{\circ} \mathrm{C}$ in a transcription reaction $(20 \mu \mathrm{l})$ containing $0.5 \mathrm{mM} \mathrm{ATP}, 0.5 \mathrm{mM}$ CTP, $0.5 \mathrm{mM}$ GTP, $0.25 \mathrm{mM}$ UTP, $\left[{ }^{35} \mathrm{~S}\right] \mathrm{UTP} \alpha \mathrm{S}, 40 \mathrm{U}$ of RNase inhibitor (Toyobo), and $20 \mathrm{U}$ of T7 RNA polymerase with provided reaction buffer (Promega).

\section{UV crosslinking assays}

An aliquot of nuclear extracts ( $5 \mu \mathrm{g}$ estimated protein) was incubated (in $25 \mu \mathrm{l}$ ) for $30 \mathrm{~min}$ at $25^{\circ} \mathrm{C}$ in the I.B. [12 mM HEPES- $\mathrm{NaOH}(\mathrm{pH} 7.9)$, $60 \mathrm{mM} \mathrm{KCl}, 4 \mathrm{mM} \mathrm{MgCl}$, $1 \mathrm{mM}$ EDTA, $1 \mathrm{mM}$ EGTA, $1 \mathrm{mM}$ DTT, $10 \%$ glycerol, and $1 \mathrm{mM} \mathrm{PMSF]}$ with $10 \mu \mathrm{g}$ tRNA and each of the ${ }^{35}$ S-labeled RNA probes $(1 \mu \mathrm{g})$. This reaction mixture was UV irradiated $(254 \mathrm{~nm}$, $60 \mathrm{~W}$ ) for $15 \mathrm{~min}$ at room temperature. Free probes were digested for 30 
min at $25^{\circ} \mathrm{C}$ with $10 \mu \mathrm{g}$ RNase $\mathrm{A}$, followed by the addition of a four-fold volume of SDS-PAGE sample dye mixture [10 mM Tris- $\mathrm{HCl}(\mathrm{pH} 6.8), 10 \%$ glycerol, $2 \%$ sodium dodecyl sulfate (SDS), $0.01 \%$ bromophenol blue, and $5 \%$ 2-mercaptoethanol]. This sample mixture was separated by SDSPAGE (15 or $10-20 \%$ gradient of polyacrylamide). Gels were fixed, dried, and analyzed by Bio Imaging Analyzer (BAS-5000; Fujifilm Medical Systems). Experiments were repeated at least four times using separate cell cultures and we obtained consistent results.

\section{Purification and identification of HMGA1a}

An outline of the purification procedure and fraction designations are depicted in Figure 3a. Nuclear extracts from SK-N-SH cells subjected to hypoxia (described above) were precipitated in $60 \%$ saturated-ammonium sulfate. Pooled supernatants were dialyzed twice in $5 \mathrm{I}$ of $50 \mathrm{mM}$ Tris- $\mathrm{HCl}$ buffer ( $\mathrm{pH} 7.5$ ) for $4 \mathrm{~h}$ at $4{ }^{\circ} \mathrm{C}$ and applied to a DEAE column chromatography (Pharmacia). The column was washed with $10 \mathrm{ml}$ of

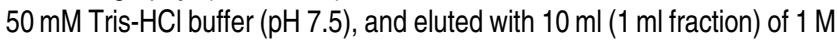
$\mathrm{NaCl}$ in $50 \mathrm{mM}$ Tris- $\mathrm{HCl}(\mathrm{pH}$ 7.5). Strong binding activity to the No. $5 \mathrm{RNA}$ probe was recovered in the third $1 \mathrm{ml}$ fraction after the start of $1 \mathrm{M}$ salt elution. This fraction was dialyzed twice in $5 \mathrm{I}$ of $50 \mathrm{mM}$ Tris- $\mathrm{HCl}$ buffer $(\mathrm{pH}$ 7.5), and applied to an affinity column using $5^{\prime}$-amino-2'-0-methyl RNA (5'-AUCUUCUUGGUGGUGCUCUACAAGUACCGCUGCUACAAGGUGAGGCCCU-3') coupled with CNBr-activated Sepharose 4B (Pharmacia). The column was washed with $10 \mathrm{ml}$ I.B., and eluted with $15 \mathrm{ml} \mathrm{I.B.}$ containing $1 \mathrm{M} \mathrm{NaCl}$. The eluted fraction was dialyzed twice in $5 \mathrm{I}$ of Milli-Q water. The dialysate was lyophilized, and dissolved in $1 \mathrm{ml}$ Milli-Q water containing $0.1 \%$ trifluoroacetic acid (TFA). This solution was then separated by reverse-phase chromatography using a 5C18-MS column (4.6 $\mathrm{mm} \times 150 \mathrm{~mm}$; Waters), and washed with Milli-Q water containing $0.1 \%$ TFA. Elution was performed using a $25 \mathrm{ml}$ linear gradient $(0-100 \%)$ of acetonitrile in Milli-Q water containing $0.1 \%$ TFA, followed by $5 \mathrm{ml}$ of $100 \%$ acetonitrile containing $0.1 \%$ TFA. Fractions containing a single peak (eluting at $20-25 \%$ acetonitrile) were pooled $(0.5 \mathrm{ml})$. After examining its homogeneity by SDS-PAGE, the entire pooled fraction was separated by electrophoresis on a $12 \%$ SDS-PAGE. The gel pieces of visible single band was excised and digested with trypsin. The eluted polypeptide fragments were separated by HPLC using a TSK gel ODS-80Ts QA column $(2.0 \mathrm{~mm} \times 250 \mathrm{~mm}$; Tosho) and analyzed in an automated protein sequencing (G1005A; Hewlett Packard).

As a result of the partial peptide sequencing, we obtained a sequence of consecutive 17 amino acids (KQPPVSPGTALVGSQKE). Based on this sequence, database was searched for sequence homology using FASTA and BLAST tools. This search resulted in a perfect match to human HMGA1a (formerly HMG-I) (DDBJ/EMBL/GenBank accession No. L17131(1)). The identified 17-amino acid fragment coincided with the HMGA1a polypeptide sequence from Lys 31 to Glu 47. The purified protein was not HMGA1b, an alternative spliced variant of HMGA1a, because it lacks the sequence from Val 35 to Gln 45 .

\section{Northern blotting assays}

Northern blotting assays were performed as previously described. ${ }^{25}$

\section{Immunoblotting assays}

Immunoblotting was performed as previously described ${ }^{42,43}$ with minor modifications. Anti-HMGA1 (HMG-I(Y) (N-19)) and anti-U1-70K (U1 SnRNP 70 (C-18)) goat polyclonal antibodies were purchased (Santa Cruz Biotechnology). Anti-U1A rabbit polyclonal antibody (\#856) and anti-U1-C mouse monoclonal antibody (\#943) were generous gifts from $\mathrm{Dr} S$ Gunderson.

\section{Immunocytochemical assays}

Immunocytochemical assays were performed using SK-N-SH cells as described ${ }^{25}$ with minor modifications. Briefly, SK-N-SH cells, subjected to normoxia or hypoxia for $21 \mathrm{~h},{ }^{11}$ were fixed in $4 \%$ paraformaldehyde for $2 \mathrm{~h}$ at room temperature and soaked in $0.3 \%$ Triton-X100 for at least $5 \mathrm{~min}$. Fixed permeable cells were washed three times in PBS and incubated with an anti-HMGA1 (HMG-I/Y) antibody (Santa Cruz Biotechnology) and antiSC35 antibody (Sigma) for $12 \mathrm{~h}$ at $4^{\circ} \mathrm{C}$. Cells were then washed three times in PBS, followed by incubation with FITC-conjugated anti-goat IgG and Cy3-conjugated anti-mouse IgG antibody (Jackson Laboratory) for $2 \mathrm{~h}$ at room temperature. Proteins were visualized using a $488 \mathrm{~nm}$ excitation filter under a PC-computer-equipped microscope (Carl Zeiss).

\section{Immunoprecipitation and immunohistochemical assays}

Immunoprecipitations were performed as previously described. ${ }^{11}$ Briefly, normoxia- or hypoxia-exposed SK-N-SH cells were recovered $24 \mathrm{~h}$ after the stimulation. A portion $(100 \mu \mathrm{g})$ of the hypoxia SK-N-SH cells were treated with $30 \mathrm{U}$ of micrococcal nuclease (Takara) for $30 \mathrm{~min}$ at $30^{\circ} \mathrm{C}$. Prepared nuclear fractions and micrococcal nuclease-treated nuclear fractions were immunoprecipitated by an anti-HMGA1 (HMG-I/Y) antibody, followed by immunoblotting assay using an anti-U1-70K antibody. Same nuclear fractions were immunoprecipitated by an anti-U1-70K antibody, followed by immunoblotting assay using an anti-HMGA1 antibody.

Immunohistochemical assays were performed using the immunoperoxidase method described previously. ${ }^{12}$ At least three different hippocampus tissues from controls and sporadic $A D$ patients were analyzed and each gave consistent results.

\section{Analysis of cell viability (cell death assay)}

SK-N-SH cells were transfected with $5 \mu \mathrm{g} \mathrm{HMGA1a}$, followed by treatment with $1 \mu \mathrm{g} / \mathrm{ml} \mathrm{TM}$ for $10 \mathrm{~h} .24 \mathrm{~h}$ after transfection, the cell viability were determined using a commercial kit according to the manufacturer's protocol (CellTiter 96 AQueous One Solution Cell Proliferation assay; promega).

\section{Acknowledgements}

The authors gratefully acknowledge Dr K Ogita for his advice on protein purification techniques, Ms A Arakawa for her help, and APRO Science Co., Ltd, for their assistance in peptide sequencing. We are grateful to Drs. N. Mori (Hamamatsu Medical University), T. Inagaki (Shimane Medical University) and the Netherlands Brain Bank for the use of brain samples and to Dr. S. Gunderson for the expression at plasmids and antibodies of U1-A and U1-C. We thank Drs. C.T. Moraes, F. Huijing, R.K. Fujimura, W. Scott, and K. Ohe for critical reading of the manuscript; Drs. A.R. Krainer and M.P. Deutscher for valuable discussions and encouragement. AM was supported by the Institutional Research Grant (IRG-98-277-04) from ACS and the Florida Biomedical Research Program Grant (BM031) from FDH. AM is a research member of the Sylvester Comprehensive Cancer Center. 


\section{References}

1. Selkoe DJ (1994) Normal and abnormal biology of the beta-amyloid precursor protein. Annu. Rev. Neurosci. 17: 489-517

2. Goate A, Chartier-Harlin MC, Mullan M, Brown J, Crawford F, Fidani L, Giuffra L, Haynes A, Irving N, James L, Mant R, Newton P, Rooke K, Roques P, Talbot C, Pericak-Vance M, Roses A, Williamson R, Rossor M, Owen M and Hardy J (1991) Segregation of a missense mutation in the amyloid precursor protein gene with familial Alzheimer's disease. Nature 349: 704-706

3. Rogaev El, Sherrington R, Rogaeva EA, Levesque G, Ikeda M, Liang Y, Chi H, Lin C, Holman K, Tsuda T, Mar L, Sorbi S, Nacmias B, Poacentini S, Amaducc L, Chumakov L, Cohem D, Lannfelt L, Fraser PE, Rommeus JM and St George-Hyslop P (1995) Familial Alzheimer's disease in kindreds with missense mutations in a gene on chromosome 1 related to the Alzheimer's disease type 3 gene. Nature 376: 775-778.

4. Wang Y-C, Selvakumar M and Helfman DM (1997) Alternative pre-mRNA splicing. In Eukaryotic mRNA Processing, Krainer AR, (ed) (Oxford: IRL Press) pp. 242-279

5. Cooper TA and Mattox W (1997) The regulation of splice-site selection, and its role in human disease. Am. J. Hum. Genet. 61: 259-266

6. Lopez AJ (1998) Alternative splicing of pre-mRNA: developmental consequences and mechanisms of regulation. Annu. Rev. Genet. 32: 279-305

7. Hutton $\mathrm{M}$, Lendon $\mathrm{CL}$, Rizzu $\mathrm{P}$, Baker M, Froelich $\mathrm{S}$, Houlden $\mathrm{H}$, PickeringBrown S, Chakraverty S, Isaacs A, Grover A, Hackett J, Adamson J, Lincoln S, Dickson D, Davies $P$, Petersen RC, Stevens M, de Graaff E, Wauters E, van Baren J, Hillebrand M, Joosse M, Kwon JM, Nowotny P, Kuei Che L, Norton J, Morris JC, Reed LA, Trojanowski J, Basun H, Lannfelt L, Neystst M, Fahn S, Dark F, Tannenberg T, Dodd PR, Hayward N, Kwok JBJ, Schofield PR Andreadis A, Snowden J, Craufurd D, Neary D, Owen F, Oostra BA, Hardy J, Goate A, van Swieten J, Mann D, Lynch T and Heutink P (1998) Association of missense and $5^{\prime}$-splice-site mutations in tau with the inherited dementia FTDP. 17. Nature 393: 702-705

8. Buratti E, Dork T, Zuccato E, Pagani F, Romano M and Baralle FE (2001) Nuclear factor TDP-43 and SR proteins promote in vitro and in vivo CFTR exon 9 skipping. EMBO J. 20: 1774-1784

9. Tysoe C, Whittaker J, Xuereb J, Cairns NJ, Cruts M Van Broeckhoven C, Wilcock $G$ and Rubinsztein DC (1998) A presenilin-1 truncating mutation is present in two cases with autopsy-confirmed early-onset Alzheimer disease. Am. J. Hum. Genet. 62: 70-76

10. Perez-Tur J, Froelich S, Prihar G, Crook R, Baker M, Duff K, Wragg M, Busfield F, Lendon C, Clark, RF, Rogues P, Fuldner RA, Johnston J, Cowburn R, Forsell C, Axelman K, Lilius L, Houlden H, Karran E, Roberts GW, Rossor M, Adams MD, Hardy J, Goate A, Lannfelt L and Hutton M (1995) A mutation in Alzheimer's disease destroying a splice acceptor site in the presenilin-1 gene. Neuroreport 7: 297-301

11. Sato N, Hori O, Yamaguchi A, Lambert JC, Chartier-Harlin MC, Robinson PA, Delacourte A, Schmidt AM, Furuyama T, Imaizumi K, Tohyama M and Takagi T (1999) A novel presenilin-2 splice variant in human Alzheimer's disease brain tissue. J. Neurochem. 72: 2498-2505

12. Sato N, Imaizumi K, Manabe T, Taniguchi M, Hitomi J, Katayama T, Yoneda T, Morihara T, Yasuda Y, Takagi T, Kudo T, Tsuda T, Itoyama Y, Makifuchi T, Fraser PE, St George-Hyslop P and Tohyama M (2001) Increased production of $\beta$-amyloid and vulnerability to endoplasmic reticulum stress by an aberrant spliced form of presenilin-2. J. Biol. Chem. 276: 2108-2114

13. Manabe T, Katayama T, Sato N, Kudo T, Matsuzaki M, Imaizumi $K$ and Tohyama M (2002) The cytosolic inclusion bodies that consists of splice variants that lack exon 5 of the presenilin-2 gene differ obviously from Hirano Bodies observed in the brain from sporadic cases of Alzheimer's disease patients. Neurosci. Let. 328: 198-200

14. Bustin $M$ (2001) Revised nomenclature for high mobility group (HMG) chromosomal proteins. Trends Biochem. Sci. 26: 152-153

15. Reeves R (2001) Molecular biology of HMGA proteins: hubs of nuclear function. Gene 277: 63-81

16. Eckner R and Birnstiel ML (1989) Cloning of cDNAs coding for human HMG I and HMG Y proteins: both are capable of binding to the octamer sequence motif. Nucleic Acids Res. 17: 5947-5959

17. Spector DL, Fu X-D and Maniatis T (1991) Associations between distinct pre-mRNA splicing components and the cell nucleus. EMBO J. 10: 3467-3481
18. Misteli T and Spector DL (1998) The cellular organization of gene expression. Curr. Opin. Cell Biol. 10: 323-331

19. Krämer A (1996) The structure and function of proteins involved in mammalian pre-mRNA splicing. Annu. Rev. Biochem. 65: 367-409

20. Will $C L$ and Lührmann $R$ (1997) snRNP structure and function. In Eukaryotic mRNA Processing, Krainer AR, (ed) (Oxford: IRL Press) pp. $130-173$

21. Burge CB, Tuschl T and Sharp PA (1999) Splicing of precusors to mRNAs by the spliceosomes. In The RNA World, 2nd edn, Gesteland RF, Cech TR and Atkins JF, (eds) (Cold Spring Harbor: Cold Spring Harbor Laboratory Press) pp. $525-560$

22. Kohtz JD, Jamison SF, Will CL, Zuo P, Lührmann R, Garcia-Blanco MA and Manley JL (1994) Protein-protein interactions and $5^{\prime}$-splice-site recognition in mammalian mRNA precursors. Nature 368: 119-124

23. Wu JY and Maniatis T (1993) Specific interactions between proteins implicated in splice site selection and regulated alternative splicing. Cell 75: 1061-1070

24. Berget SM (1995) Exon recognition in vertebrate splicing. J. Biol. Chem. 270: 2411-2414

25. Katayama T, Imaizumi K, Sato N, Miyoshi K, Kudo T, Hitomi J, Morihara T, Yoneda T, Gomi F, Mori Y, Nakano Y, Takeda J, Tsuda T, Itoyama $Y$, Murayama O, Takashima A, St George-Hyslop P, Takeda M and Tohyama M (1999) Presenilin-1 mutations downregulate the signalling pathway of the unfolded-protein response. Nat. Cell. Biol. 1: 475-485

26. Lin CL,Bristol LA, Jin L, Dykes-Hoberg M, Crawford T, Clawson $L$ and Rothstein JD (1998) Aberrant RNA processing in a neurodegenerative disease: the cause for absent EAAT2, a glutamate transporter, in amyotrophic lateral sclerosis. Neuron 20: 689-602.

27. Kalaria RN (2002) Small vessel disease and Alzheimer's dementia: pathological considerations. Cerebrovasc. Dis. 13 (Suppl 2): 48-52

28. Thanos $D$ and Maniatis $T$ (1995) Virus induction of human IFN gene expression requires the assembly of an enhanceosome. Cell 83: 1091-1100

29. Falvo JV, Thanos D and Maniatis T (1995) Reversal of intrinsic DNA bends in the IFN $\beta$ gene enhacer by transcription factors and the architectural protein HMG I(Y). Cell 83: 1101-1111

30. Mayeda A, Helfman DM and Krainer AR (1993) Modulation of exon skipping and inclusion by heterogeneous nuclear ribonucleoprotein $A 1$ and pre-mRNA splicing factor SF2/ASF. Mol. Cell Biol. 13: 2993-3001 (published erratum in 4458).

31. Blanchette M and Chabot $B$ (1999) Modulation of exon skipping by high-affinity hnRNP A1-binding sites and by intron elements that repress splice site utilization. EMBO J. 18: 1939-1352

32. Cáceres JF, Stamm S, Helfman DM and Krainer AR (1994) Regulation of alternative splicing in vivo by overexpression of antagonistic splicing factors. Science 265: 1706-1709

33. Birney E, Kumar S and Krainer AR (1993) Analysis of the RNA-recognition motif and $R S$ and $R G G$ domains: conservation in metazoan pre-mRNA splicing factors. Nucleic Acids Res 21: 5803-5816

34. Fu X-D. (1995) The superfamily of arginine/serine-rich splicing factors. RNA 1: $663-680$

35. Labourier E, Adams MD and Rio DC (2001) Modulation of P-element premRNA splicing by a direct interaction between PSI and U1 snRNP 70K protein. Mol. Cell 8: 363-373

36. Martelli AM, Riccio M, Bareggi R, Manfioletti G, Tabellini G, Baldini G, Narducci $P$ and Giancotti V (1998) Intranuclear distribution of HMGI/Y proteins. An immunocytochemical study. J. Histochem. Cytochem. 46: 863-864

37. Phillips $C$, Jung $S$ and Gunderson $S I$ (2001) Regulation of nuclear poly(A) addition controls the expression of immunoglobulin M secretory mRNA. EMBO J. 20: 6443-6452

38. Schreiber E, Matthias P, Muller MM and Schaffner W (1989) Rapid detection of octamer binding proteins with 'mini-extracts', prepared from a small number of cells. Nucleic Acids Res. 17: 6419

39. Yoneda Y, Ogita K, Azuma Y, Ikeda M, Tagami H and Manabe T (1999) Nmethyl-D-aspartate signaling to nuclear activator protein-1 through mechanisms different from those for kainate signaling in murine brain. Neuroscience 90: 519-533

40. Yoneda $\mathrm{Y}$, Ogita K, Azuma Y, Kuramoto N, Manabe T and Kitayama T (1999) Predominant expression of nuclear activator protein-1 complex 
with DNA binding activity following systemic administration of $\mathrm{N}$-methyl$\mathrm{D}$-aspartate in dentate granule cells of murine hippocampus. Neuroscience 93: 19-31

41. Manabe T, Kitayama T, Ogita $K$ and Yoneda $Y$ (2000) Differential expression and phosphorylation of particular Fos family members by kainate in nuclear and cytosolic fractions of murine hippocampus. Neuroscience 100: 453-463
42. Manabe T, Kuramoto N, Nakamichi N, Aramachi K, Baba K, Hirai T, Yoneyama $\mathrm{M}$ and Yoneda $\mathrm{Y}$ (2001) Degradation of c-Fos protein expressed by N-methylD-aspartic acid in nuclear fractions of murine hippocampus. Brain Res. 905: $34-43$

43. Manabe T, Ogita $\mathrm{K}$, Nakamichi $\mathrm{N}$ and Yoneda $\mathrm{Y}$ (2001) Differential in vitro degradation of particular Fos family members expressed by kainic acid in nuclear and cytosolic fractions of murine hippocampus. J. Neurosci. Res. 64: 34-42 